\title{
La prisión provisional en la doctrina del Tribunal Constitucional
}

Manuel Rodríguez López

Presidente de la Audiencia Provincial de Málaga

La Constitución Española en su artículo 17 dice:

$1^{2}$ Toda persona tiene derecho a la libertad y a la seguridad. Nadie puede ser privado de su libertad, sino con la observancia de lo establecido en este artículo y en los casos y en la forma previstos por la Ley.

$2^{\circ}$ La detención preventiva no podrá durar más del tiempo estrictamente necesario para la realización de las averiguaciones tendentes al esclarecimiento de los hechos, $\mathrm{y}$, en todo caso, en el plazo máximo de setenta y dos horas, el detenido deberá ser puesto en libertad o a disposición de la autoridad judicial.

$3^{2} \mathrm{La}$ Ley regulará un procedimiento de "habeas corpus" para producir la inmediata puesta a disposición judicial de toda persona detenida ilegalmente. así mismo, por ley se determinará el plazo máximo de duración de la prisión provisional.

El Tribunal Constitucional en sentencia de 19-XII-1985, dijo: "El artículo 17 de la Constitución no concibe la libertad individual como un derecho absoluto no susceptible de restricciones, lo que ocurre es que sólo la Ley puede establecer los casos y las formas en que la restricción o privación de libertad es posible".

$Y$ en sentencia de 2 de julio de 1982, ha dicho: "El mandato Constitucional español relativo a los principios de libertad y seguridad, encuentran sus precedentes en las Constituciones Españolas de 1812 (art. 290), de 1837 (art. 7), de 1845 (art. 7), de 1869 (art. 2), de 1873 (art.4), de 1876 (art. 4) y de 1931 (art. 29), y en los instrumentos internacionales siguientes: Declaración Universal de Derechos Humanos de 1948 (Acta 9), convenio para la protección de los Derechos Humanos y de las Libertades Fundamentales de 1950 (art. 5) y Pacto Internacional de los Derechos Civiles y Políticos de 1966 (art. 9)".

El Tribunal Europeo de los Derechos Humanos distingue dos mo- 
mentos en la privación de la libertad, la detención inicial para la que basta la existencia de indicios de infracción y la prolongación de la detención que sólo puede hacerse en supuestos concretos. Ello quiere decir que la inicial privación de libertad, para esclarecer los hechos, puede acordarse en las primeras diligencias, con los meros indicios y que la estabilización en el tiempo de dicha medida requiere mayores exigencias.

\section{Detención}

Esta misma distinción la encontramos en nuestro derecho positivo, cuando regula separadamente la detención y la prisión preventiva.

La detención es una medida cautelar de tipo personal que -como dice Muñoz Conde - supone la privación transitoria de la libertad de una persona por un breve periodo de tiempo, determinado en su extensión máxima.

La detención, igual que la prisión preventiva, entraña una privación de libertad y por tanto ha de tener carácter excepcional.

Ningún español ni extranjero podrá ser detenido sino en los casos y las formas que las leyes prescriben (art. 489 L. E. Criminal).

La detención la puede practicar cualquier persona, en determinados supuestos: (art. 490 L. E. Cr.).

$1^{9}$ Para impedir que se cometa un delito.

$2^{9} \mathrm{Al}$ que se fugare de una prisión, se fugare durante la conducción o se fugare estando detenido o preso, por causa pendiente.

$3^{2} \mathrm{Al}$ procesado o condenado que estuviere en rebeldía.

Y tiene la obligación de practicarla la Autoridad o los agentes de la Policía Judicial en los casos anteriormente referidos (art. 492 de la L. E. Cr.), y:

$1^{2} \mathrm{Al}$ que estuviere procesado por delito que tenga señalada en el Código pena superior a la prisión menor.

$2^{\circ} \mathrm{Al}$ procesado por delito al que esté señalada pena inferior a prisión menor si sus antecedentes o las circunstancias del hecho, hicieren presumir que no comparecerá cuando fuere llamado por la Autoridad Judicial.

$3^{2} \mathrm{Al}$ que estuviera en el caso anterior, aunque todavía no se hallase procesado, con tal que concurran las dos circunstancias siguientes: $1^{\mathrm{B}}$ 
Que la Autoridad o agente tenga motivos racionales bastantes para creer en la existencia de un hecho que presente caracteres de delito. $2^{\mathrm{a}}$ Que los tengan también bastantes para creer que la persona a quien intenta detener tuvo participación en él.

También puede llevarse a efecto la detención para hacer comparecer a una persona ante la Autoridad Judicial, por desobediencia a una orden Judicial al acusado, testigo o perito que no compareciere, después de haber sido citado en forma.

Hay otros supuestos en los que se puede llevar a efecto la detención y en su caso el internamiento, como pueden ser:

I. Al menor de edad penal, conforme a la Ley de 4 de julio de 1948 .

II. Al presunto incapaz, conforme al artículo 211 del Código Civil.

III. Al extranjero para su expulsión, en los casos previstos en la Ley.

IV. Al extranjero, respecto del cual se haya interesado la extradición, conforme a la Ley de 21 de marzo de 1985.

V. Al quebrado, conforme al artículo 1.044-2 $2^{\circ}$ del Código de Comercio de 1829 , que regula la quiebra. Medida de vieja tradición en nuestro ordenamiento jurídico, cuya constitucionalidad fue declarada por sentencia del Tribunal Constitucional de 19 de diciembre de 1985.

El Tribunal Constitucional en sentencia de 10 de julio de 1986, nos dice que debe considerarse como detención cualquier situación en que la persona se ve implicada u obstaculizada para autodeterminar, por obra de su voluntad, una conducta lícita, de suerte para la detención no es una decisión que se adopte en el curso de un procedimiento, sino una pura situación fáctica, sin que puedan encontrarse zonas intermedias entre detención y libertad.

$Y$ en sentencia de 31-I-1986, viene a marcar el alcance o límite a aquella libertad al señalar que el artículo $17-1^{2}$ de la Constitución comporta la ausencia de perturbaciones procedentes de medidas tales como la detención u otras similares que, adoptadas arbitraria o ilegalmente, restringen o amenazan la libertad de toda persona de organizar en cualquier momento y lugar del territorio nacional su vida individual y social con arreglo a sus propias opciones y convicciones.

En garantía del derecho a la libertad la Constitución en su art. 17$4^{2}$ mandó regular el procedimiento de "habeas corpus", para la inmediata puesta a disposición judicial de toda persona detenida.

Mandato que se cumplió con la Ley Orgánica 6/1984 de 29 de mayo 
que estableció un procedimiento rápido para conseguir la inmediata verificación de la legalidad y las condiciones de la detención.

$Y$ en su artículo 25-3 de la Constitución se dispone que la Administración no podrá imponer sanciones que directa o subsidiaramente impliquen privación de libertad.

\section{Prisión provisional}

\section{Concepto}

La Prisión Provisional, como la denomina la Constitución Española y la Ley de Enjuiciamiento Criminal o Prisión Preventiva, como la llama el Código Penal y la Ley Orgánica General Penitenciaria, es una medida procesal tendente a asegurar los fines del procedimiento criminal y eventualmente la ejecución de la sentencia y que consiste en la privación de libertad del acusado, mediante su ingreso en un establecimiento adecuado, normalmente un establecimiento penitenciario.

La Prisión Provisional no puede entenderse, en modo alguno, como pena anticipada, pues no tiene ni siquiera la consideración legal de pena, a tenor del artículo 26 del Código Penal.

\section{Antecedentes históricos}

La Prisión como institución jurídica — según dice Bernaldo de Quirós, Enciclopedia Jurídica Seix - tiene sus primeras manifestaciones en los postes naturales $o$ artificiales, para la inmovilización de una persona, mediante el sistema de ligaduras del sometido a ella.

Así - según dicho autor- el árbol que, en las zonas campestres de Marruecos, sirve frente a frente del así ento del jeque juzgador, para amarrar a los reos juzgados hasta el momento de la ejecución del castigo.

$\mathrm{Y}$ todos hemos visto la imagen cinematográfica del árbol que sirve en determinas cintas, para amarrar al reo.

Y también hemos oído hablar de la picota, como lugar, en la entrada de los pueblos, donde se exponía a los reos a la vergüenza pública.

Pero cuando, por consecuencia de las complicaciones jurídicas y sociales, el juicio sufrió mayor dilación, cuando el plazo que media 
entre la detención y el juicio se hizo mayor, la prisión se convirtió en recintos cerrados, en los que, de una parte, las condiciones de seguridad, y de otra, la desconsideración abusiva frente al presunto reo, dieron los caracteres de oscuridad, de incomodidad y de tristeza propias que desde entonces tienen las prisiones.

La Prisión Provisional, como institución fue conocida en el Derecho Romano, donde Tulio Hostilio fundó la primera cárcel, a la que siguió la Claudina y la Mamertina, que - como dice Carrara, Programa de Curso de Derecho Penal- no se utilizará para la ejecución de penas, si no como medida de custodia previa al juicio.

La prisión en dichas épocas sólo tenía una función preventiva, era un medio para impedir la fuga de los que aguardaban el juicio.

Así en las Partidas, la Ley Cuarta del Título XXV de la Séptima Partida, expresa claramente este carácter cuando dice: "La cárcel no es dada para escarmentar los yerros, mas para guardar los presos solamente en ella, fasta que sean juzgados".

Como dice Seelig - Tratado de Criminología, Madrid 1958, hasta el establecimiento de las "casas de corrección" en el siglo XVI, la cárcel es una medida estrictamente procesal.

A partir de este momento, la prisión toma un nuevo carácter, carácter que todavía tiene;' pese a la reacción doctrinal contraria a ella, como pena típica y casi única de los Códigos contemporáneos.

\section{Fundamento}

En el tiempo en que estuvo vigente en el procedimiento criminal el principio inquisitivo, la prisión del inculpado, durante el desarrollo del proceso, era la regla general y la libertad provisional era la excepción, pues la acusación presuponía la culpabilidad: el acusado en principio era responsable penal del delito que se imputaba.

Pero después, cuando se parte del principio de presunción de inocencia, la justificación de la prisión preventiva se hace teniendo en cuenta los intereses generales de la sociedad que ha de salvaguardar el Estado.

Hoy es claro que el derecho a la libertad está considerado como un derecho inherente a la persona humana y está consagrado en las legislaciones como un derecho fundamental. 
Derecho que sólo puede someterse a limitaciones en cuanto pueda entrar en colisión con el derecho a la seguridad que el Estado viene obligado a mantener.

La justificación que tiene la prisión preventiva, como medida restrictiva de la libertad personal, es la de evitar que el acusado obstaculice la investigación sumarial, y, en definitiva, el cumplimiento, en su día, de la pena que pudiera corresponderle.

En las postrimerías del siglo XIX, con el estilo cálido y retórico, propio de la época y la vehemencia de su celo de reformadora - como dice el Magistrado D. Jesús Fernández Entralgo, en su artículo "El sentido de la prisión provisional", publicado en la Revista General del Derecho- se lamentaba Concepción Arenal diciendo: "Imponer a un hombre una pena tan grande como la privación de libertad, una mancha en su honra como es haber estado en la cárcel, y esto sin haberle probado que es culpable y con la posibilidad de que sea inocente, es cosa que dista mucho de la justicia".

Frente a esta postura, Aguilera de Paz —en sus Comentarios a la Ley de Enjuiciamiento Criminal - decía: "Algunos autores, guiados por sentimientos de humanidad exagerados y erróneos, han demandado la abolición de la prisión preventiva, pero esto haría imposible el ejercicio de la justicia. Ninguna razón sólida puede autorizar dicha impugnación, pues si bien es cierto que la prisión preventiva es un mal, hay que reconocer que constituye un mal menor, necesario e irremplazable".

El Profesor Pérez Gordo-citado por Fernández Entralgo, en su referido trabajo- ha resumido esta solución de compromiso diciendo: "Hay que reconocer que repugna a cualquier conciencia el que se pueda privar de libertad a quien todavía se presume inocente", pero añade "si fundamental es el derecho a la libertad personal, no es menos el derecho a la seguridad, y se refiera ésta al ciudadano o la sociedad".

\section{Fundamento y concepto en la doctrina del Tribunal Constitucional}

Para el Tribunal Constitucional la prisión provisional es una institución situada entre el deber estatal de perseguir eficazmente el delito y el deber estatal de asegurar el ámbito de libertad del ciudadano (S. 2-VII-1982), pues entiende que no existen derechos ilimitados, todos 
tienen sus límites, unas veces impuestos por la propia Constitución y otras derivados de una manera mediata o indirecta de tal Norma, en cuanto han de justificarse por la necesidad de proteger o preservar no sólo otros derechos constitucionales, sino también otros intereses constitucionalmente protegidos, siendo el límite de cada derecho el de respetar el derecho de los demás (SS.- 29-I-1982 y 8-IV-1981).

Y en la sentencia de 12 de marzo de 1987 (S. N 32/1987) después de recoger la anterior doctrina, dice: "Ciertamente es necesario reiterar ahora que, aún reconociendo su carácter de simple medida cautelar, que sin prejuzgarlo, tiende a asegurar el resultado final del proceso, la prisión provisional es una decisión judicial de carácter excepcional que incide negativamente en el "status" de libertad personal del inculpado y por lo mismo, es con toda evidencia restrictiva del derecho fundamental reconocido en los apartados $1^{9}$ y $4^{9}$ del artículo 17 de la Constitución".

En la sentencia de 3 de abril de 1987, después de decir que las normas de los artículos 503 y 504 de la Ley de Enjuiciamiento Criminal deben aplicarse a la luz de los principios y normas constitucionales añade que tanto estas normas como las internacionales que, de conformidad con el artículo 10-2 de nuestra Constitución han de servir de base a la interpretación de las normas legales: artículos 3,9 y $11-1^{\circ}$ de la Declaración Universal de los Derechos Humanos; artículos 5 y 6-2 ${ }^{\circ}$ del Convenio para Protección de los Derechos Humanos y de las Li-

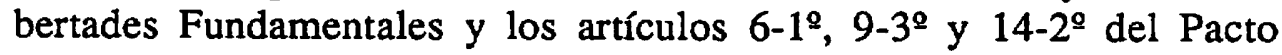
Internacional de Derechos Civiles y Políticos. De ellos se desprenden los principios de: a) Interdicción de la arbitrariedad de cualquier detención o prisión; b) Presunción de inocencia; c) Limitación temporal de la media de prisión hasta un plazo razonable; d) Justificación de la medida para asegurar la comparecencia del acusado al acto del juicio, en su caso, para la ejecución del fallo, o para impedir otra infracción, y en fin, e) Excepcionalidad de la medida cautelar de prisión, que no debe ser la regla general.

Y en la sentencia de 8 de julio de 1987, reitera el carácter de simple medida cautelar de la prisión provisional, su aspecto restrictivo del derecho a la libertad y por ello de situación de excepcionalidad para acabar recogiendo la doctrina de dicho Tribunal, "en materia de derechos fundamentales la legalidad ordinaria ha de ser interpretada de la forma más favorable para la efectividad de tales derechos". 
Para dicho Tribunal la prisión provisional es una medida cautelar (SS-2-VII-82 y 12-III-87) tendente a asegurar el resultado final del proceso (S. 12-III-87 y 8-VII-87) y la comparecencia del inculpado (S. 3-IV-87) que respetando el principio de presunción de inocencia (S. 3IV-87), puede ser adoptada por decisión judicial (S. 2-VII-82, 3-IV87), en un proceso penal (S. 3-IV-87), en resolución fundada (S. 12-III87), medida cautelar, que no puede entenderse como pena y sin embargo va más allá del carácter procesal, pues restringe el derecho fundamental a la libertad (SS. 12-III-87, I-IV-87, 3-IV-82 y 8-VIII-87) y duración temporal, (S. 3-IV-87 y 8-VII-87) medida que se ha adoptado para los casos y dentro de los limites establecidos por la Ley, por lo que está vedada la arbietariedad (S. 3-IV-87), debiendo interpretarse las normas que la regulan en la forma más faborable al derecho fundamental a la libertad del inculpado (S. 2-VII-82, 12-III-87, 3-IV-87 y 8-VII-87) y de conformidad con la doctrina del Tribunal Constitucional y de los Organismos Internacionales para la Protección de los Derechos Humanos y Libertades Fundamentales.

\section{Carácter discrecional}

Admitida por los tratadistas el principio de la necesidad de la prisión provisional, estos "difieren - según decía Aguilera de Paz, en sus comentarios a la Ley de Enjuiciamiento Criminal- notablemente en cuanto a las medidas de llevarla eficazmente a la práctica en su reglamentación procesal y mientras unos entienden que la potestad otorgada a la Autoridad judicial para decretar la Prisión del Presunto culpable no debe tener más límites que su prudente y discrecional criterio, para que en cada caso, con arreglo a las circunstancias del mismo, determine lo que su conciencia y celo por la realización de la justicia le dicten; otros, por el contrario, estiman peligrosa en extremo toda libertad en este punto, y sostienen que la Ley debe condicionar de una manera expresa y terminante el ejercicio de esta potestad, estableciendo taxativamente los casos en que procede dicha prisión, para evitar los abusos a que pudiera dar lugar el libre arbitrio judicial en esta materia".

Es claro que este segundo sistema fue el adoptado en la Ley de Enjuiciamiento Criminal de 14 de septiembre de 1882, si bien con un 
"sentido amplio, expansivo y liberal", como decía su Exposición de Motivos.

$Y$ es también el que actualmente rige en nuestra legislación.

La Ley de Enjuiciamiento Criminal en sus artículos 503 y 504 establece:

Para decretar la prisión provisional serán necesarias las circunstancias siguientes:

$1^{9}$ Que conste en la causa la existencia de un hecho que presente los caracteres de delito.

$2^{2}$ Que éste tenga señalada pena superior a la de prisión menor, o bien que, aún cuando tenga señalada pena de prisión menor o inferior, considere el juez necesaria la prisión provisional, atendidos los antecedentes del imputado, las circunstancias del hecho, la alarma social que su comisión haya producido o la frecuencia con que se cometen hechos análogos. Cuando el juez haya decretado la prisión provisional en caso de delito que tenga prevista pena inferior a la de prisión mayor, podrá según su criterio, dejarla sin efecto, si las circunstancias tenidas en cuenta hubiesen variado, acordando la libertad del inculpado con o sin fianza.

$3^{9}$ Que aparezcan en la causa motivos bastantes para creer responsable criminalmente del delito a la persona contra quien se haya de dictar el auto de prisión.

Procederá también la prisión provisional cuando concurran la primera y la tercera circunstancia del artículo anterior y el inculpado no hubiera comparecido, sin motivo legítimo, al primer llamamiento del juez o Tribunal o cada vez que éste lo considere necesario.

No obstante lo dispuesto en el artículo anterior, aunque el delito tenga señalada pena superior a la de prisión menor, cuando el inculpado carezca de antecedentes penales o estos deban considerarse cancelados y se pueda creer fundadamente que no tratará de sustraerse a la acción de la justicia, y además, el delito no haya producido alarma ni sea de los que se cometen con frecuencia en el territorio donde el juez o Tribunal que conociere de la causa ejerce su jurisdicción, podrán estos acordar mediante fianza, la libertad del inculpado.

La situación de prisión provisional no durará más de tres meses cuando se trate de causa - por delito al que corresponde pena de arresto mayor, ni más de un año cuando la pena sea de prisión menor o de dos 
años cuando la pena sea superior. En estos dos últimos casos, concurriendo circunstancias que hagan prever que la causa no podrá ser juzgada en estos plazos y que el inculpado pudiera sustraerse a la acción de la Justicia, la prisión podrá prolongarse hasta dos y cuatro años, respectivamente. La prolongación de la prisión provisional se acordará mediante auto, con audiencia del inculpado y del Ministerio Fiscal.

Una vez condenado el inculpado, la prisión provisional podrá prolongarse hasta el limite de la mitad de la pena impuesta en la sentencia cuando esta hubiere sido recurrida.

No se tendrá en cuenta, para el cómputo de los plazos establecidos en este articulo, el tiempo en que la causa sufriere dilaciones no imputables a la Administración de Justicia.

Contra los autos que decretan la prisión provisional o los que disponga su prolongación o libertad provisional podrán ejercitarse los recursos de reforma y apelación.

Concedida la libertad por transcurso de los plazos máximos previstos para la prisión provisional será también de aplicación lo dispuesto en el párrafo primero de este artículo.

Es de señalar que, en líneas generales, con excepción de haberse establecido los plazos máximos de duración de la prisión provisional la redacción actual de estos preceptos, de conformidad con la Ley Orgánica 10/1984 de 26 de diciembre, coincide sustancialmente con la redacción que le fue dada en el texto originario de la Ley de Enjuiciamiento Criminal de 14 de septiembre de 1882, aunque en la vigente redacción se amplian las razones para poder determinar la prisión provisional, cuando el delito tenga señalada pena no superior a prisión menor, en atención a la "alarma social" o la "frecuencia" de la comisión de hechos análogos. También se permite al juez dejar sin efecto la prisión, con fianza o sin ella, cuando las circunstancias hayan cambiado. Y se admite la posibilidad de acordar la prisión si no compareciere el inculpado sin motivo legítimo, cada vez que el juez o Tribunal lo llame.

E igualmente da mayor flexibilidad para acordar la libertad, en el supuesto en el que el delito esté penado con pena superior a prisión menor, cuando los antecedentes penales puedan considerarse cancelados. 
Este mismo criterio de conservar en lo sustancial la primitiva redacción, se ha mantenido en las sucesivas reformas de los referidos artículos, a los que se le fueron añadiendo párrafos que se referían, por influencias del momento político predominante, a determinados delitos valorando la naturaleza y las circunstancias de los mismos, para poder determinar la posibilidad de aplicación de la prisión provisional, pero los requisitos esenciales de los artículos 503 y 504 de la Ley de Enjuiciamiento Criminal, quedaban inalterados.

Sin embargo en la Ley de 22 de abril de 1980, el legislador, impulsado por razones coyunturales de política criminal, modificó sustancialmente dichos preceptos, lo que justificó diciendo en el Preámbulo de la Ley, "las circunstancias hoy concurrentes de aumento de cierto tipo de delincuencia, que sin ser de extrema gravedad atenta la tranquilidad ciudadana... hace aconsejable un mayor rigor de las medidas provisionales que el juez puede decretar para asegurar la persona del detenido".

Para ello dispuso: "El juez decretará la prisión provisional cuando concurran las circunstancias...". En consecuencia al emplear el imperativo, el juez debia automáticamente decretar la prisión. Y como también modificó el artículo 503, expresando "que el delito tenga señalada pena superior a la de arresto mayor", es claro que la prisión preventiva dejó de ser la medida excepcional para convertirse en la regla general, desvirtuando el verdadero sentido y función de la prisión provisional.

Situación que permaneció vigente hasta la entrada en vigor de la Ley Orgánica 7/1983 de 23 de abril. El objeto de esta Ley - según Preámbulo, "consiste en cumplir el mandato recogido en el artículo 17$4^{2}$, último inciso, de la Constitución que establece que por Ley se determinará el plazo máximo de duración de la prisión provisional y recoger el principio de que la situación de prisión provisional debe tener carácter excepcional, no pudiendo convertirse en una ejecución anticipada de la pena, ni tener el carácter obligatorio". Con ello se pretende sustituir el sistema que limitaba el arbitrio judicial, introducido por la Ley 10/1980 de 22 de abril.

En dicha Ley 6/1983 se fijó la duración máxima de la prisión provisional en seis meses cuando el delito imputado lleve aparejada pena igual o inferior a prisión menor y dieciocho meses en los demás casos.

Esta Ley estuvo vigente hasta la entrada en vigor de la referida Ley de 26 de diciembre de 1984. 
"Tres reformas producidas en cinco años que, como dice Montero Aroca, han consistido en un tejer destejer".

Quién puede acordar la prisión provisional y cuándo.

A tenor de los artículos 502 y siguientes de la Ley de Enjuiciamiento Criminal:

Corresponde al juez de Instrucción, o al que formule las primeras diligencias, o actúe por comisión o interinamente, decretar la prisión privisional, mientras dure el estado de sumario y al Tribunal cuando esté conociendo de la causa.

También corresponde al juez de Instrucción decretar la prisión cuando conozca de las Diligencias de la Ley Orgánica 10/1980 o de Diligencias Preparatorias.

La Prisión provisional ha de acordarse por auto (arts. 141 y 504).

El Tribunal Constitucional, en sentencia de 2 de julio de 1982 dice resolución judicial motivada.

Para poder acordar la prisión provisional es necesario:

A) Que conste la existencia de un hecho que revista los caracteres de delito. No cabe acordarla en los juicios por faltas.

B) Que aparezcan en la causa motivos suficientes para creer responsable criminalmente del delito a la persona contra quien se haya de acordar la prisión provisional.

C) Como regla general, que el delito imputado esté castigado con pena superior a prisión menor. Como excepciones a esta regla general:

I.- Estando sancionado el delito con pena no superior a prisión menor, se podrá acordar la prisión provisional, cuando concurran una de las circunstancias siguientes:

a) Que el inculpado no comparezca, sin motivo legítimo, cuando sea llamado por el juez o Tribunal.

b) Que el juez considere necesaria la prisión provisional, atendidas los antecedentes del inculpado, las circunstancias del hecho, la alarma social que la comisión del delito hubiere producido o la frecuencia con que se cometan hechos análogos.

II.- Estando sancionado el delito con pena superior a prisión menor, se permite la libertad provisional del inculpado, mediante fianza cuando éste carezca la antecedentes penales, o estos deban considerarse y se 
pueda creer fundamentalmente que no se tratará de sustraerse a la acción de la justicia y, además, el delito no haya producido alarma social ni sea de los que se cometen con frecuencia en el territorio de la jurisdicción del juez o Tribunal que conociera de la causa.

El Tribunal Constitucional, en sentencia de 3 de abril de 1987, dice: "Cierto es que la Ley encomienda, dentro de la función jurisdiccional que le es propia a los jueces y tribunales la potestad de acordar sobre la situación de libertad o de prisión preventiva respecto de aquellas personas sujetas a un proceso penal y antes de la celebración del juicio oral, teniendo en cuenta para ello las circunstancias subjetivas y objetivas que concurran en el caso, tales como la naturaleza del delito, la gravedad mayor o menor de la posible pena pedida o que pueda pedirse, las características del hecho y de su posible prueba en la fase sumarial con la presencia obligada del inculpado, la posibilidad de huída de éste, etc. En este sentido la Ley Procesal Penal (articulos 503, 504 y concordantes) establecen las pertinentes reglas y la remisión de su observancia al justo arbitrio de los jueces y tribunales, los cuales, obvio es decirlo, habrán de aplicarlas con la mira siempre puesta en su mayor y directa vinculación a la Norma constitucional, sobre todo si, como en el caso, están en juego derechos fundamentales, aquí el de la libertad reconocido en el artículo $17-1^{2}$ y 4 de la Constitución. Es a la luz de los principios y normas constitucionales, en definitiva, como deben aplicarse aquellas normas legales".

\section{Mandamiento}

Para llevar a efecto el auto de prisión se expedirán dos mandamientos, uno para el Agente Judicial o funcionario de la Policia Judicial y otro para el Director del Establecimiento (art. 505).

En el mandamiento se consignará el auto de prisión, el nombre, apellido, naturaleza, estado y domicilio del inculpado, el delito que dé lugar al procedimiento, si se procede de oficio o a instancia de parte y si la prisión ha de ser con comunicación o sin ella. (art. 505).

\section{Clases de prisión}

La prisión puede ser con comunicación o sin ella. 
La incomunicación de los presos sólo podrá durar el tiempo necesario para la investigación del delito, sin que por regla general deba durar más de cinco días (art. 506).

$\mathrm{El}$ juez o Tribunal que conozca de la causa puede mandar que vuelva el inculpado a la incomunicación, después de haber sido puesto en comunicación, pero esta incomunicación no excederá de tres dias (art. 508), salvo que las citaciones hechas para la investigación hubieran de efectuarse fuera del territorio de la Península o a larga distancia, en cuyo caso la incomunicación durará el tiempo preciso para evitar la confabulación.

La Prisión provisional debe llevarse a efecto en un establecimiento penitenciario o arresto municipal, como norma general.

Si bien la prisión puede ser atenuada, cuando por razón de enfermedad del inculpado el internamiento entrañe grave peligro para su salud (art. 505).

El Código de Justicia Militar, dispone que los militares deberán ser ingresados en establecimientos militares, cuando se acuerde su prisión preventiva (C.J.M. art. 673) (en la actualidad es el artículo 215 de la Ley Orgánica Procesal militar 2/89).

\section{Recursos}

Contra el auto que decreta la prisión provisional o que disponga su prolongación o la libertad provisional, podrá ejercitarse los recursos de reforma y de apelación (art. 504).

El Tribunal Constitucional en diversas ocasiones ha admitido el recurso de amparo contra los autos de prisión o de prolongación de la misma.

El recurso de amparo es un proceso constitucional tanto por su objeto, pretensiones fundadas en normas de derecho constitucional, como por el Organo jurisdiccional a que se atribuye su conocimiento. Su finalidad es la protección de los derechos fundamentales y defensa objetiva de la Constitución y de su valor como norma suprema.

No es una tercera instancia, sino que su función se circunscribe a la protección de los derechos reconocidos en los artículos 14 al 29 y 30$2^{\circ}$ de la Constitución y la competencia del Tribunal Constitucional es 
de carácter limitado, ya que el art. $44-1^{\circ}$ b) de la Ley Orgánica del Tribunal Constitucional exige que "la violación de derecho y libertad sea imputable de modo inmediato y directo a una acción u omisión del órgano judicial, con independencia de los hechos que dieron lugar al proceso en que aquellos se produjeron, en los que, en ningún caso, entrará a conocer el Tribunal Constitucional".

Es por tanto obligado para el Tribunal Constitucional "el partir de los hechos declarados probados por las sentencias impugnadas", "lo que constituye un limite no aplicable en ningún otro supuesto de recurso de amparo" (S. 29-I-1981). En su auto N 320/1984 el T. C. dijo: "La defensa de la libertad justifica el acceso al Tribunal Constitucional".

$Y$ en sentencia de 3 de abril de 1987, manifiesta que desde la perspectiva de los principios y normas constitucionales es "como este Tribunal puede sin interferir en los hechos y en la competencia judicial, valorar la transcendencia constitucional de las decisiones que inciden en los derechos fundamentales especialmente protegidos por la Norma suprema".

\section{Reforma de oficio}

También los autos de prisión y libertad provisionales son reformables de oficio o a instancia de parte durante todo el curso de la causa (art. 539), (art. 503).

\section{Cómo debe ejecutarse la prisión}

La prisión privisional deberá practicarse en la forma que menos perjudique al preso en su persona, reputación y patrimonio (art. 520).

Esta disposición legal es lógica pues la prisión provisional, aparte del estigma social, participa de las mismas consecuencias que todo ingreso en prisión lleva consigo, que -como dice Bueno Arus, "la Dimensión jurídica de la pena de prisión", Anuario de Derecho Penal y Ciencias Penales, Tomo XI año 1987-no se limitan a la exclusivaprivación de la libertad de movimientos, puesto que afectan a otros derechos inherentes a la persona, como pueden ser la libertad de expresión, la libertad de reunión y manifestación, así como a derechos civiles, económicos, laborales y familiares, que quedan limitadas y a 
veces anulados por la propia naturaleza de la prisión y forman parte de su contenido.

\section{Duración}

La duración máxima de la prisión provisional es:

a) De tres meses, cuando se trata de causas por delitos al que corresponda pena de arresto mayor.

b) De un año, cuando la pena señalada para el delito sea de prisión menor.

c) De dos años, cuando la pena señalada para el delito sea superior a prisión menor.

El Tribunal Constitucional en sentencia de 2 de julio de 1988 recogiendo el artículo 5-3 del Convenio para la Protección de Derechos Humanos y de las Libertades Fundamentales de 1950, dijo que toda persona tiene derecho a ser juzgada en un plazo razonable o a ser puesta en libertad durante el procedimiento.

$Y$ en sentencia de 26 de diciembre de 1984, reconoció el derecho de toda persona a no ser privada de libertad, "sino con la observancia de lo establecido en el artículo 17 de la Constitución Española y en los casos y en la forma previstos en la Ley", en relación con la exigencia constitucional de fijación de un plazo máximo de duración de la prisión provisional configura un derecho fundamental a no permanecer en prisión por plazo superior al legalmente establecido.

En definitiva, lo que la Ley dice - afirma la sentencia citada- es fijar imperativamente el deber de poner en libertad al acusado transcurridos los plazos legales (S. 3-IV- 1987).

En aquella misma sentencia se afirma que en el supuesto de acumulación de sumarios por la conexión que diversos delitos tienen entre sí, no puede sostenerse que el plazo máximo y excepcional que establece la Ley para la prisión provisional, haya de contarse para cada delito por separado. Hacer depender esa duración del número de delitos imputados supone en la práctica, que en el plazo máximo fijado por la Ley dependa de un elemento incierto como es el número de delitos con que se acusa a una persona; además violaría los pactos internacionales pactados por España, una interpretación de este tipo, pues el resultado de multiplicar el plazo máximo legal de la prisión provisional 
por el número de delitos imputados conduce a un resultado notoriamente superior a todo plazo razonable. En igual sentido se expresó la sentencia de 27 de marzo de 1985.

\section{Prolongación de la prisión}

La Ley de Enjuiciamiento Criminal establece excepcionalmente la posibilidad de prolongar la prisión provisional, cuando concurran circunstancias que hagan prever que la causa no podrá ser juzgada en los plazos marcados y que el inculpado pudiera sustraerse a la acción de la justicia, señalando un máximo de dos años y cuatro años respectivamente, sin que se pueda prolongar cuando la pena señalada sea de arresto mayor.

El Tribunal Constitucional, en sentencia de 3 de abril de 1987 ha dicho: "Es incuestionable que la Sala pudo prolongar la situación procesal de la prisión preventiva antes del trascurso de dos años desde el inicio de ésta, conforme al articulo 504 de la Ley de Enjuiciamiento Criminal, si se dieron los requisitos de tal norma. Pero no lo hizo así, es decir en tiempo obligado, ni tampoco como era preceptivo, poner en libertad al procesado. Por eso, cuando a instancia de éste acuerde la prórroga de la prisión dos meses y unos días más tarde de la fecha en que se cumplió el plazo legal perentorio, ya no cabía subsanar la vulneración constitucional de la garantía de la libertad personal no respetada por la omisión del órgano judicial".

Una vez condenado el inculpado, la prisión provisional podrá prolongarse hasta el límite de la mitad de la pena impuesta en la sentencia, cuando ésta hubiera sido recurrida.

Por tanto, dictada sentencia, la prisión provisional puede tener mayor duración que antes de dictarse la sentencia; aunque ésta no es firme, el legislador ha estimado que puede existir mayor razón para mantener la prisión provisional.

Como excepción a la regla general que determina la duración máxima de la prisión, se dispone que no se tendrá en cuenta para el cómputo de los plazos establecidos en este artículo, el tiempo en que la causa sufriere dilaciones no imputables a la Administración de Justicia. En la Ley de 1983 se decía imputables al inculpado. La nueva redacción parece ampliar los supuestos en los que la dilación que sufriere la 
causa no ha de ser tenida en cuenta para el cómputo de los plazos legales.

En todo caso deberá prestarse cumplimiento al artículo 528 de la Ley de Enjuiciamiento Criminal, "La Prisión Provisional sólo durará lo que subsistan los motivos que la hayan ocasionado".

"El preso será puesto en libertad en cualquier estado de la causa en que resulte su inocencia".

"Todas las autoridades que intervengan en un proceso estarán obligadas a dilatar lo menos posible la detención y la prisión provisional de los inculpados o procesados".

En este momento es interesante recordar la Real Orden Circular de 20 de marzo de 1916 en que se comunicaba a los presidentes y fiscales, para que a su vez lo hicieren a los jueces de Instrucción, la conveniencia de que, inspirados en el verdadero propósito de la Ley, restrinjan la prisión provisional a aquellos casos en que sea absolutamente indispensable. $Y$ que procuren que en la tramitación y despacho de las causas en que haya presos, se proceda con la más extraordinaria rapidez, no consintiendo que en ningún caso se exceda de los plazos que para cada trámite marca la Ley.

La sucesión de disposiciones legales diferentes sobre el plazo máximo de prisión provisional, y al ser la Ley de 1984 más restrictiva de la libertad que la de 1983, que la precedió, ha originado que se hayan planteado diversos recursos de amparo ante el Tribunal Constitucional que si bien en los autos de 18 de diciembre de 1985 y 24 de septiembre de 1980, sostuvo que la Ley Procesal aplicable será la vigente en el momento de cada uno de los actos procesales, sin que de ello pueda derivarse una aplicación retroactiva de la Ley. Posteriormente modifica su doctrina en las sentencias 32 y 34 de 1987, de fecha 12 de marzo de 1987, y efectúa una interpretación más favorable al derecho de libertad del inculpado y asi dice: "la predicada naturaleza procesal o adjetiva de tales normas y el alcance meramente preventivo o cautelar de la prisión provisional no pueden en modo alguno ocultar la efectiva limitación de la libertad personal del inculpado en la causa penal".

$Y$ en la otra sentencia de igual fecha dijo: "Se desconocerían las garantías constitucionales frente a limitaciones indebidas del derecho a la libertad al aplicarse una Ley posterior más restrictiva a un inculpado en situación de prisión preventiva acordada con arreglo a una Ley 
anterior más benigna, pues ello podría suponer la prolongación de la situación excepcional de prisión más allá del límite máximo establecido en la Ley aplicable en el momento en que se acordó su privación de libertad, plazo máximo que representa para el afectado la garantía constitucional del derecho fundamental a la libertad de acuerdo con lo dispuesto en el apartado cuarto en relación con el apartado primero del artículo 17 de la Constitución".

\section{Efectos}

En cuanto a los efectos de la prisión provisional o preventiva hemos de señalar que aparte de los anteriormente enumerados, que afectan a derechos de libertad de opinión, reunión, manifestación, derechos civiles familiares y económicos, etc., en el Código Penal en su artículo 33 dispone que "El tiempo de prisión preventiva sufrida por el delincuente durante la tramitación de la causa se abonará en su totalidad para el cumplimiento de la condena, cualquiera que sea la clase de pena impuesta".

No faltará quien piense que con esta interpretación tan restrictiva de la prisión provisional se facilita la fuga de los delincuentes, sujetos al procedimiento. Cuestión ésta de tanta actualidad, después de las últimas fugas habidas en España, que tienen tan sensibilizada a la opinión pública, según se infiere de la lectura de los medios de comunicación.

$\mathrm{Y}$ ello es cierto, pero no debemos olvidar que como dice Aguilera de Paz, "la fuga del culpable supone privaciones terribles; sacrificios extraordinarios; la ausencia del lugar donde habitualmente se ha vivido, del centro donde se cultivan las relaciones todas de la vida, y donde radican los bienes poseídos; quizás el voluntario extrañamiento de la patria; la pérdida de la tranquilidad por el continuo temor de ser perseguido y capturado; infinidad de contratiempos, dificultades y angustias que en la mayoría de los casos exceden con mucho a la gravedad de la pena que hubiera de sufrirse, y a los inconvenientes que son su natural consecuencia".

Pero además tenemos que tener presente que nuestro país está vinculado por los Tratados Internacionales, a que anteriormente hemos hecho referencia y que nuestra legislación se ha de adaptar a lo estipulado en dichos Tratados, y a lo acordado por los Organismos que los interpretan. 


\section{Conclusión}

El Excmo. Sr. Fiscal General del Estado -en su Memoria presentada al Gobierno, en septiembre de 1987, al inicio del presente año Judicial- recogiendo la doctrina del Tribunal Constitucional, ha dicho: Las normas que regulan la libertad provisional son normas limitadoras del derecho fundamental a la libertad y que afectan a los derechos fundamentales del artículo 24-2; entre ellos la presunción de inocencia, entendiendo que de ello se derivan como consecuencias: I.- Que cabe en amparo el control del Tribunal Constitucional cuando se actúa bajo la cobertura improcedente de una ley o contra lo que la misma ley dispone. II.- Las prescripciones legales sobre la prisión provisional han de interpretarse en la forma más favorable al derecho fundamental que limitan. III.- Han de interpretarse, por último, de conformidad con los Tratados y Convenios suscritos por España, especialmente por el Convenio Europeo para la Protección de los Derechos Humanos y Libertades Fundamentales, firmado en Roma el 4 de noviembre de 1950, y por tanto atendiendo a la jurisprudencia del Tribunal Europeo de los Derechos Humanos, al que el Tribunal Constitucional, en numerosas sentencias cita y reconoce la validez obligatoria de su jurisprudencia.

Y más adelante el Excmo. Sr. Fiscal General del Estado, dice: el Tribunal Europeo de los Derechos Humanos en los Arret Wemhoff, 27 de junio de 1968, Nuemeister, 27 de junio de 1968, Stogmuller, 10 de noviembre de 1969; Maznetter, 10 de noviembre de 1969; Ringeisen, 16 de julio de 1971; Guzzardi, 10 de noviembre de 1980, entre otros, únicamente considera conformes con el Convenio las prisiones que tengan como finalidad asegurar el resultado del proceso o evitar que el sometido a la medida cometa nuevos delitos. El primera de los fines citados puede articularse en dos supuestos: A) Peligro de fuga. Es el riesgo de que el imputado deje de estar a disposición del Tribunal para el buen fin de la causa. Para calibrarlo se debe atender a diversas circunstancias: a) Gravedad de la pena a imponer. En cuanto el inculpado pueda ausentarse ante el temor de sufrirla, tiene dicho el Tribunal (caso Maznetter) que la importancia de la pena no puede por si sola hacer presumir el peligro de fuga, sino que es preciso el examen de las 
circunstancias siguientes. b) Conducta anterior, carácter y personalidad; c) Circunstancias de la detención, si ha habido singular oposición a ella; d) Arraigo familiar, profesión y arraigo económico y social en el pais que se trate. B) Peligro de supresión de pruebas. Es la posibilidad de que el imputado en libertad pueda sobornar a los testigos o amenazarlos o destruir u ocultar pruebas documentales o de otra especie. El segundo de los fines tasados es el peligro de cometer nuevas infracciones. Para determinar si existe debe tenerse en cuenta la conducta y trayectoria delictiva anterior hábitos criminales, gravedad del delito y nocividad. Esta nocividad debe entenderse como peligrosidad criminal. Es de destacar que para el Tribunal Europeo de los Derechos Humanos la gravedad del delito per se, sin conectarse con el peligro de fuga, repetición de hechos o supresión de pruebas, no puede fundamentar la medida cautelar que es la prisión provisional.

El Excmo. Sr. Fiscal General del Estado a continuación añade: Como esta doctrina es vinculante, los supuestos de los artículos 503 y 504 de la Ley de Enjuiciamiento Criminal deben sufrir una profunda reinterpretación. Las consecuencias son: I.- Los "antecedentes" y "circunstancias" del hecho deberán ahora referirse a todas las circunstancias personales y fácticas que el Tribunal Europeo de los Derechos Humanos evalúa para determinar si se da alguno de los tres peligros exigidos con carácter cerrado. II.- La "alarma social" y "frecuencia" no deben aplicarse por los Jueces como fundamento de la privación cautelar de la libertad por su dificultad a ser encajados con los referidos peligros. III.- La gravedad de la pena no es por sí criterio fundamentador de la medida a no ser que se conexione al peligro de fuga valorado además por las circunstancias personales. IV.- En los supuestos de prisión reglada, penas de prisión mayor con alguna de las circunstancias expresadas en la Ley, alarma, antecedentes, etc. cuando el único peligro sea el de fuga cabrá la posibilidad de fianza (por aplicación directa del art. 5-3 del Convenio). V.- Los autos de prisión provisional sólo serán constitucionales cuando se funden en alguno de los tres citados peligros, debidamente probados y no presumidos, así como suficientemente razonados en la resolución.

Sin embargo a diario vemos autos de prisión que no se ajustan a las orientaciones que señala el Excmo. Sr. Fiscal General del Estado y ello es lógico pues como ha dicho el Excmo. Sr. D. Enrique Ruiz Vadillo 
-algunas consideraciones sobre el sistema acusatorio y de interdicción constitucional de toda indefensión en el proceso penal, la Ley $n^{2} 1826$, 23-X-1987- "Acaso hayan de pasar muchos años para que nos demos perfecta cuenta del profundo cambio que se ha operado en España, aparte de, en otros órdenes, en el jurídico y de la forma tan eficaz como se ha producido. Nuestra Constitución promulgada en diciembre de 1978, todavía no hace ni siquiera una década ha supuesto una mutación sustancial en todo el Ordenamiento Jurídico, no sólo en aquella parte formalmente derogada o modificada, sino también, y en no pequeña medida, en aquella que ha permanecido inalterada. Hasta aquí ha llegado el influjo de nuestra Ley Fundamental, a veces con inconstitucionalidades sobrevenidas, más espectaculares, pero no siempre complejas, y a veces con una incidencia determinante, conforme a la doctrina constante y reiterada del Tribunal Constitucional, de nuevas interpretaciones, más acordes con los principios y mandatos de la Ley de Leyes". 